\title{
IMPLEMENTASI GOOGLE MAPS API DENGAN PHP DAN MYSQL (KASUS : SISTEM INFORMASI PARIWISATA)
}

\author{
Agus Sidiq Purnomo \\ Jurusan Teknik Informatika, Fakultas Teknologi Informasi, UniversitasMercu Buana Yogyakarta \\ Jalan Jembatan Merah No.84. C. Gejayan, Yogyakarta 55283 \\ sidiq.umby@mercubuana-yogya.ac.id
}

\begin{abstract}
Yogyakarta is one of the provinces which became a tourist destination. There are so many tourist objects that have not been known by tourists, both the location and how to access that must be taken towards the attraction. Therefore, the information technology (IT) can be used to indicate the location of tourist attractions making it easier for travelers to reach the tourist attractions.

As an initial step of literature used to collect various data about tourism. This app is designed based on the site map that was set before continuing with the implementation of applications using $P H P$ and MYSQL.

This study focused on the use of the Google Maps API to show a map of the area attractions based on the coordinates of the region.
\end{abstract}

Keywords: Google Maps API, Tourism, Information Systems

\section{PENDAHULUAN}

\subsection{LATAR BELAKANG}

Daerah Istimewa Yogyakarta merupakan salah satu provinsi yang menjadi tujuan wisata. Banyak sekali obyek-obyek wisata yang belum dikenal oleh wisatawan, baik lokasi maupun bagaimana akses yang harus ditempuh menuju obyek wisata tersebut.

Dengan adanya teknologi informasi (TI) yang berkembang sangat pesat, hadir dengan berbagai produk teknologi di bidang tersebut. Teknologi informasi sudah menjadi kebutuhan nyata, baik dalam konteks perseorangan maupun organisasi, serta telah menjadi bagian yang tak terpisahkan dari peningkatan daya saing dan pelayanan serta menjadi semakin berperan dalam proses pengambilan kebijakan.

\subsection{RUMUSAN MASALAH}

Berdasarkan latar belakang dirumuskan permasalahan sebagai berikut :

1. Bagaimana membantu dan mempermudah penyampaian informasi kepada masyarakat mengenai berbagai letak dari berbagai obyek wisata yang ada.
2. Bagaimana mengimplementasikan Google Maps API secara dinamis, dalam suatu sistem informasi berbasis $P H P$ dan $M y S Q L$.

\subsection{BATASAN PERMASALAHAN}

Berdasarkan rumusan permasalahan, batasan permasalahan dari sistem yang akan dibuat adalah sebagai berikut :

1. Membangun sebuah aplikasi yang dapat menampilkan data dan informasi yang terkait dengan berbagai jenis obyek wisata di Yogyakarta.

2. Pemanfaatan Google Maps API untuk menampilkan peta lokasi dari obyek wisata di Yogyakarta.

3. Lingkup permasalahan dari penyajian data terbatas terhadap data-data yang telah tersedia.

\subsection{TUJUAN DAN MANFAAT}

Tujuan dari penelitian adalah :

1. Mengenal lebih baik tentang berbagai obyek wisata di wilayah Yogyakarta.

2. Melakukan pengolahan informasi mengenai kepariwisataan. 
3. Melakukan implementasi Google Maps API ke dalam sistem informasi yang dibuat dengan menggunakan database dinamis $M y S Q L$ dan pemrograman $P H P$.

Manfaat dari penelitian ini adalah :

1. Memberikan informasi mengenai berbagai obyek wisata yang ada di wilayah Yogyakarta.

2. Memberikan pengetahuan umum tentang tempat wisata dan letaknya.

3. Dapat dijadikan sebagai bahan ajar mengenai cara implementasi Google Maps API ke dalam aplikasi sistem informasi yang dibuat dengan menggunakan database dinamis $M y S Q L$ dan pemrograman $P H P$.

\section{TINJAUAN PUSTAKA}

\subsection{TINJAUAN PUSTAKA}

Penelitian sebelumnya yang terkait dengan penelitian ini adalah penelitian yang dilakukan oleh Iwan Handoyo Putro dkk (2010) dengan judul "Peta Interaktif Untuk Sistem Informasi Wisata". Dalam penelitian ini dibuat sebuah fasilitas peta interaktif untuk membantu wisatawan mencari rute menuju tempat yang diinginkan yang diintegrasikan dengan sistem informasi pariwisata.

Taufik Nurdiawan dkk (2012) dalam penelitian yang berjudul "Aplikasi Informasi Pariwisata Berbasis Multimedia (Studi Kasus : Kota Cilacap)". Dalam penelitian ini dibuat suatu sistem informasi yang menyajikan informasi pariwisata berbasis $w e b$, yang dibuat dengan menggunakan aplikasi $P H P$ dengan mengandalkan fitur Google Maps untuk menunjukkan lokasi obyek wisata.

\subsection{SISTEM INFORMASI}

Sistem informasi mencakup sejumlah komponen (manusia, komputer, teknologi informasi dan prosedur kerja), ada sesuatu yang diproses (data menjadi informasi), dan dimaksudkan untuk mencapai sasaran atau tujuan (Kadir, 2002).
Dalam penelitian ini definisi dari sistem informasi adalah mengumpulkan dan mengolah berbagai data mengenai kepariwisataan yang dapat digunakan sebagai informasi mengenai barbagai obyek wisata yang ada.

\subsection{GOOGLE MAPS API}

Google Maps API merupakan fasilitas dari Google yang dapat digunakan untuk menambahkan peta ke dalam website dengan menggunakan JavaScript .

Google Maps API menyediakan banyak fasilitas dan utilitas untuk memanipulasi peta dan menambahkan konten ke peta melalui berbagai layanan.

\section{METODE PENELITIAN}

Penelitian ini dilakukan dengan menggunakan studi pustaka mengenai datadata mengenai daftar link-link terkait dan informasi yang relevan mengenai jenis-jenis wisata yang terdapat di Yogyakarta.

Selanjutnya dilakukan proses perancangan sistem menggunakan (peta situs) dan perancangan database.

\subsection{PETA SITUS}

Peta situs ini merupakan menu awal dari aplikasi ini. Dalam menu ini terdapat menu home, bencana, about, provinsi, informasi, antisipasi dan search. Peta situs tersebut dapat dilihat pada Gambar 1.

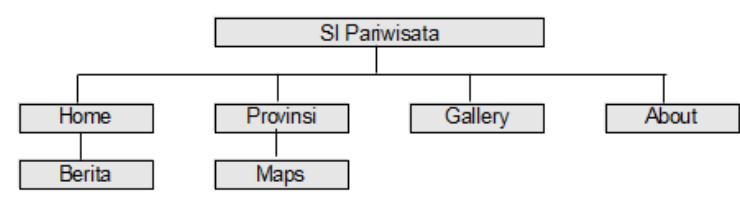

Gambar 1. Peta situs

\subsection{PERANCANGAN DATABASE}

Relasi antar tabel ini menggambarkan kerelasian antar tabel yang terdapat dalam database. Rancangan database ini terdiri dari 
1. Tabel user, digunakan untuk konfigurasi user yang terlibat dalam sistem.

2. Tabel t_berita, digunakan untuk menyimpan postingan berita wisata.

3. Tabel t_kategori_berita, digunakan untuk menyimpan kategori berita.

4. Tabel t_modul, digunakan untuk konfigurasi sistem.

5. Tabel t_infowisata, digunakan untuk menyimpan informasi wisata secara detail.

6. Tabel t_wisata, digunakan untuk menyimpan informasi tempat wisata beserta gambar.

7. Tabel t_linkterkait, digunakan untuk menyimpan link-link yang terkait dengan informasi wisata.

8. Tabel t_provinsi, digunakan untuk menyimpan informasi dan konfigurasi latitude dan longitude maupun zoom default dari Google Maps.

9. Tabel t_hubungi, digunakan untuk menyimpan pesan dari pengguna.

Rancangan relasi tabel dapat dilihhat pada Gambar 2.
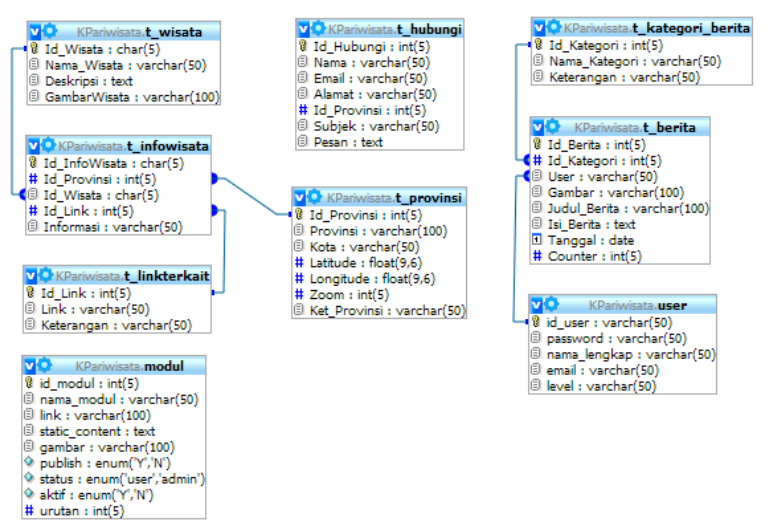

Gambar 2. Perancangan database

\section{HASIL DAN PEMBAHASAN}

Berdasarkan perancangan dan implementasi yang telah dilakukan berdasarkan data-data dan informasi yang sudah ada, dapat dilihat seperti berikut.

\subsection{HALAMAN INFORMASI}

Informasi yang berkaitan dengan tempattempat wisata di Yogyakarta dapat dilihat pada Gambar 3.

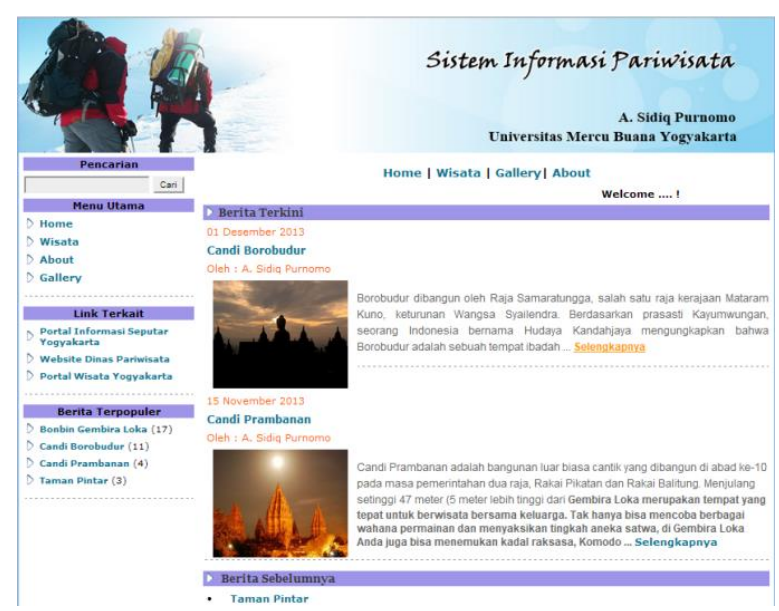

Gambar 3. Halaman Informasi

\subsection{PETA PARIWISATA DENGAN GOOGLE MAPS}

Sedangkan untuk penerapan Google Maps API dapat dilihat pada Gambar 4.

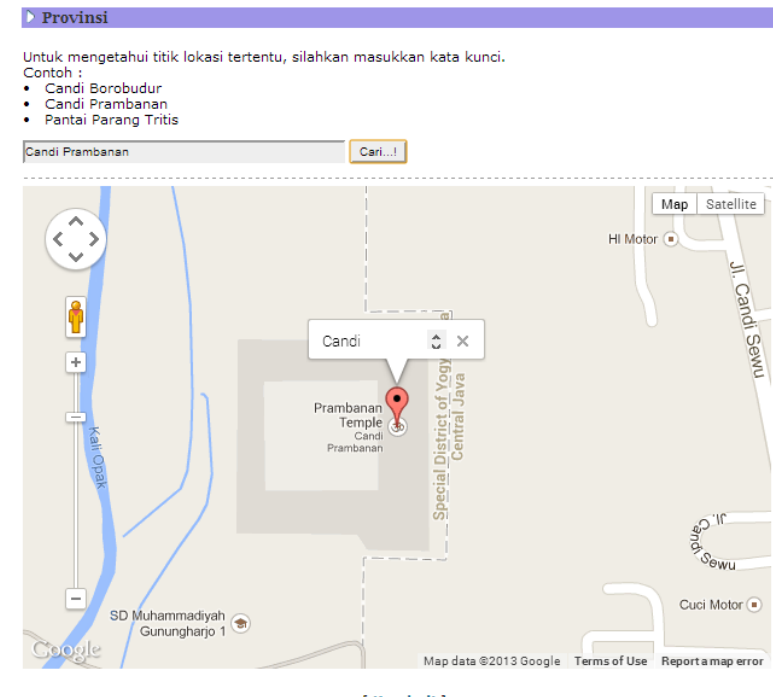

Gambar 4. Penerapan Google Maps API

\subsection{ALUR PROSES INTEGRASI DATABASE DENGAN PHP DAN GOOGLE API}

Untuk alur proses dari database dengan mengunakan PHP yang diintegrasikan 
dengan Google Maps dapat dilihat pada Gambar 5.

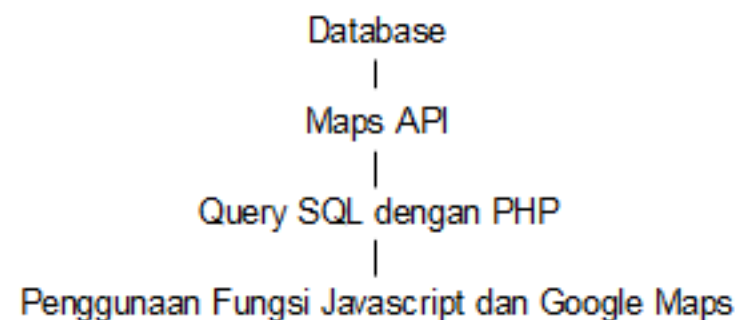

Gambar 5. Alur proses integrasi database dengan PHP dan Google Aps

\subsection{IMPLEMENTASI DATABASE DENGAN PHP DAN GOOGLE API}

API dengan database dan PHP, berikut langkah-langkah yang harus dilakukan :

\section{Database}

Database digunakan untuk menyimpan latitude dan longitude dari area maps yang akan ditampilkan dalam aplikasi web. Sebagai contoh berikut data latitude dan longitude dari beberapa provinsi di Indonesia seperti yang terlihat pada Tabel 1.

Tabel 1. Contoh latitude dan longitude

\begin{tabular}{|r|l|r|r|r|r|r|}
\hline Id_Provinsi & \multicolumn{1}{|c|}{ Provinsi } & Kota & Latitude & Longitude & Zoom & Ket_Provinsi \\
\hline 1 & NANGGROE ACEH DARUSSALAM & & 5.351273 & 95.562370 & 9 & \\
\hline 2 & SUMATERA UTARA & & 2.115355 & 99.545097 & 7 & \\
\hline 3 & SUMATERA BARAT & & -0.739940 & 100.800003 & 9 & \\
\hline 4 & RIAU & & 0.886826 & 101.706825 & 8 & \\
\hline 5 & JAMBI & & -1.485183 & 102.438057 & 8 & \\
\hline 6 & SUMATERA SELATAN & & -3.319437 & 103.914398 & 8 & \\
\hline 7 & BENGKUUU & & -3.800649 & 102.256203 & 9 & \\
\hline 8 & LAMPUNG & & -4.558585 & 105.406807 & 8 & \\
\hline 9 & KEP BANGKA BELITUNG & & -2.741051 & 106.440590 & 8 & \\
\hline 10 & KEP RIAU & & 1.045626 & 104.030457 & 10 & \\
\hline 11 & DKI JAKARTA & & -6.211544 & 106.845169 & 11 & \\
\hline 12 & JAWA BARAT & & -7.090911 & 107.668884 & 8 & \\
\hline 13 & JAWA TENGAH & & -7.150975 & 110.140259 & 8 & \\
\hline 14 & DI YOGYAKARTA & Yogyakarta & -7.797224 & 110.368797 & 10 & Ibu Kota Provinsi \\
\hline
\end{tabular}

2. Google Maps API

Google Maps API digunakan untuk integrasi web dengan Google MAPS.

\section{Listing Google Maps AP}

\section{$<$ script}

src="http://maps.google.com/maps?file=api\&v=2\&key=A BQIAAAA4ydcf3cns_MFpKKYxK3LkRT2yXp_ZAY8_ufC 3CFXhHIE1NvwkxR⿳亠口冋02dmWTvkjuenNU5vyliDqBEQA

" type="text/javascript"></script $>$

$<$ style type="text/css">
3. Modul untuk menampilkan data provinsi Modul ini digunakan untuk menampilkan provinsi berdasarkan latitude dan longitude yang terdapat di dalam database.

\section{Modul data provinsi}

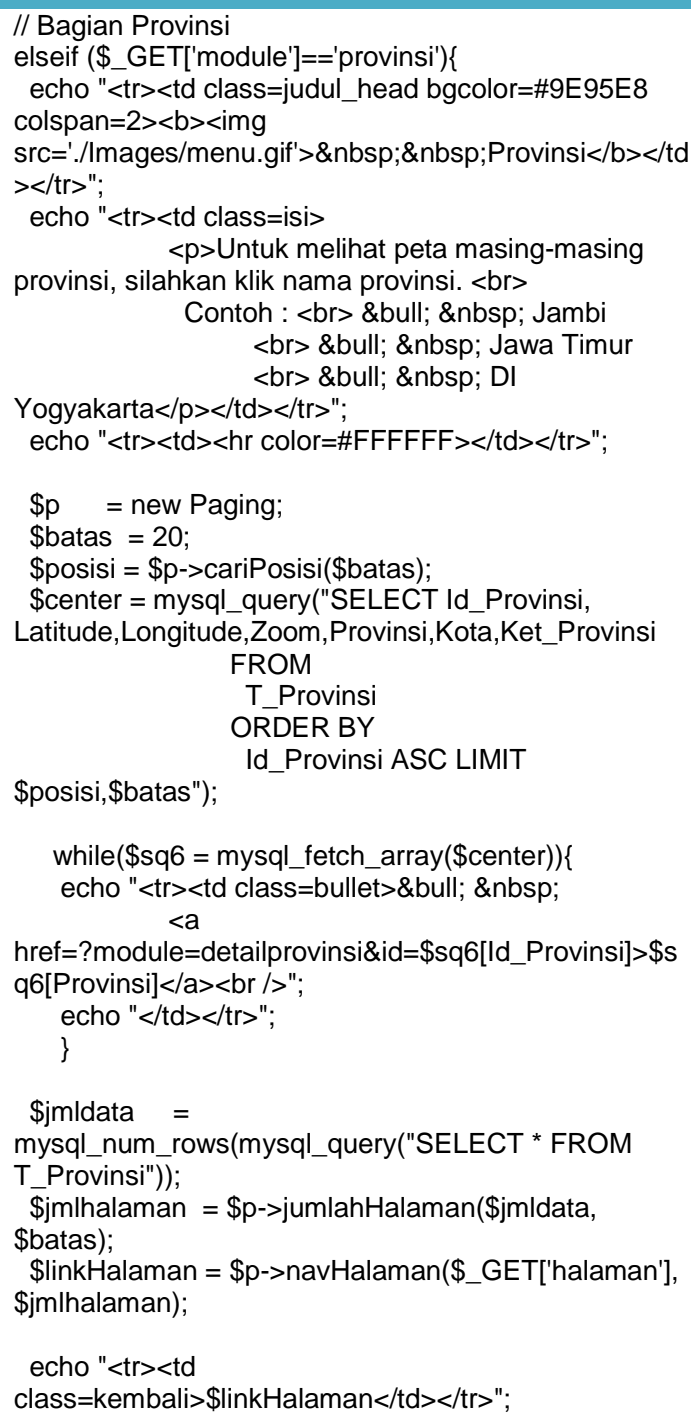

4. Modul untuk menampilkan detail dari maps

Modul ini digunakan untuk melakukan pencarian detail dari maps sesuai dengan kata kunci pencarian.

\section{Modul maps}

//Detail Latitude

elseif (\$_GET['module']=='detailprovinsi')\{

echo " $<$ tr $><$ td class=judul head

bgcolor $=\# 9$ E95E8 $><b><$ img

src='./Images/menu.gif'>\&nbsp;\&nbsp;Provinsi $</$ b $></$ td $></$ tr $>$;

\$cari3=mysql query("SELECT * FROM T Provinsi 


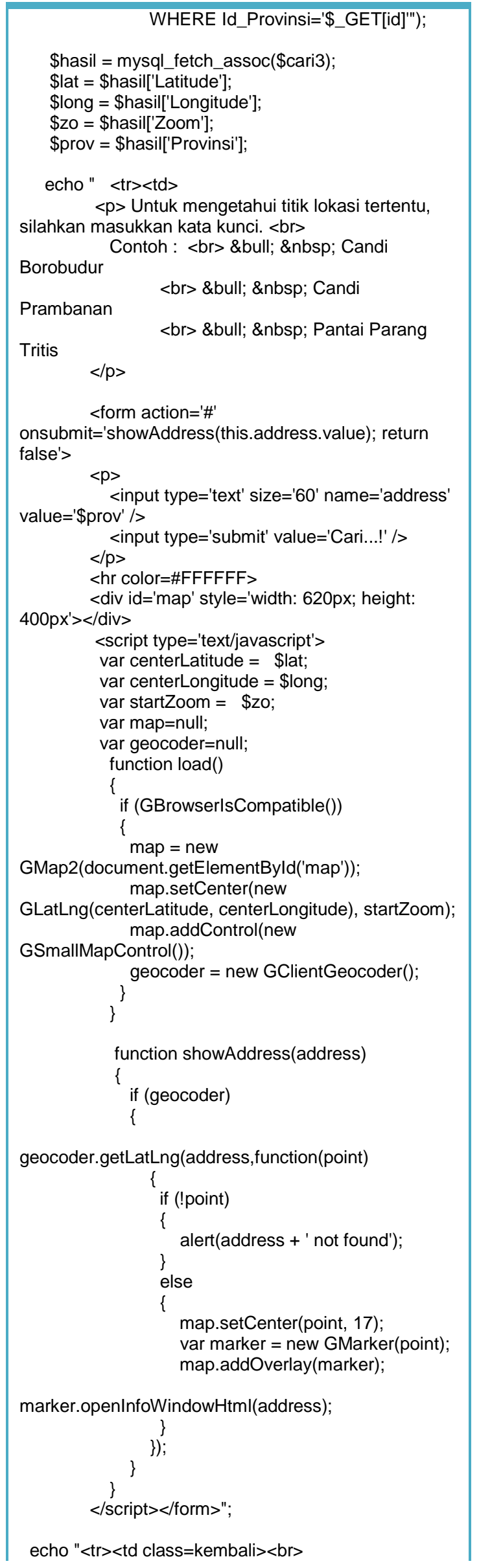

[ $<$ a href=javascript:history.go(-1) $>$ Kembali $</$ a $>$ \}

\section{KESIMPULAN DAN SARAN}

\subsection{KESIMPULAN}

Google Maps API adalah fasilitas dari Google yang dapat digunakan untuk menambahkan peta ke dalam website. Google Maps API dapat ditambahkan ke website menggunakan JavaScript. API tersebut menyediakan banyak fasilitas dan utilitas untuk memanipulasi peta dan menambahkan konten ke peta melalui berbagai layanan, memungkinkan untuk membuat aplikasi peta yang kuat pada website.

\subsection{SARAN}

Pemanfaatan Google Maps API dalam menampilkan informasi mengenai lokasi tempat-tempat wisata, perlu dikembangkan lagi, mengingat fasilitas yang disediakan Google Maps API sudah cukup beragam seperti penambanan informasi mengenai detail dari masing-masing lokasi serta beberapa keterangan mengenai lokasi yang saling terintegrasi dengan maps.

\section{DAFTAR PUSTAKA}

Google Code., 2009, Map V3 Tutorial, http://code.google.com/apis/maps/docu mentation/v3/introduction.html\#Intro.

Kadir, Abdul., 2002, Konsep Sistem Informasi,Yogyakarta : Penerbit Andi.

Nurdiawan, Taufik., dkk., 2012, Aplikasi Informasi Pariwisata Berbasis Multimedia (Studi Kasus : Kota Cilacap), Bandung : Politeknik Telkom Bandung.

Pimpler, Eric., 2009, Mashup Mania with Google Maps, Version 5: Updated January 2009, Geospatial Training Services, LLC.

Putro, I.H., dkk., 2010, Peta Interaktif Untuk Sistem Informasi Wisata, Yogyakarta : SNATI, ISSN : 1907-5022.

Svennerberg, Gabriel., 2010, Beginning Google Maps Api 3, Apress. 